Ethos: Jurnal Penelitian dan Pengabdian kepada Masyarakat, Vol 8, No.1, Juni 2019: 41-48

\title{
Optimasi Iterasi dan Root Means Square (RMS) dalam Penentuan Batas LitOlOGI DARI VERTIKAL ELEKTRICAL SOUNDING (VES)
}

\author{
${ }^{1}$ Noor Fauzi Isniarno, ${ }^{2}$ Muhammad Reyhand Alfarrel, ${ }^{3}$ Bagea Bagja Gumelar \\ ${ }^{1,2,3}$ Universitas Islam Bandung, Bandung, Jawa Barat, Indonesia \\ Email :noorfauzi@unisba.ac.id/noor_fauzi_isniarno@yahoo.com
}

\begin{abstract}
The absence of outcrops in the field will make difficulties in interpreting geoelectric data. To be able to determine the lithological limit below the surface, a geoelectric resistivity method with a Schlumberger (Vertical Electrical Sounding) configuration with different iteration and Root Mean Square (RMS) is used. Measurements were made with 4 geoelectric points and at the first point 2 intersections were intersected with each stretch length of 50 meters. Data processing is done manually and continued using PROGRESS software to interpret data and adjust iteration and Root Mean Square (RMS). Based on the results of the interpretation of the intersection between stretch 1 and stretch 2 depict the inside of the Top Soil and the iteration obtained will be a reference to interpret the next geoelectric data.
\end{abstract}

Keywords: geoelectrical method, schlumberger configuration, iteration, $R M S$

\begin{abstract}
Abstrak.Tidak terdapatnya singkapan dilapangan akan membuat kesulitan dalam menginterpretasi data geolistrik. Untuk dapat mengetahui batas litologi dibawah permukaan digunakan metode geolistrik tahanan jenis dengan konfigurasi schlumberger (Vertical Electrical Sounding) dengan perbedaan iterasi dan Root Mean Square (RMS). Pengukuran dilakukan dengan 4 titik geolistrik dan pada titik pertama dilakukan 2 bentangan secara berpotongan dengan masing - masing panjang bentangannya 50 meter. Pengolahan data dilakukan secara manual dan dilanjutkan menggunakan perangkat lunak PROGRESS untuk menginterpretasi data dan menyesuaikan iterasi dan Root Mean Square (RMS). Berdasarkan hasil interpretasi perpotongan antara bentangan 1 dan bentangan 2 menggambarkan kedalam dari Top Soil dan iterasi yang didapatkan akan menjadi acuan untuk menginterpretasi data geolistrik selanjutnya.
\end{abstract}

Kata Kunci : metode geolistrik, konfigurasi schlumberger, Iterasi, RMS

\section{Pendahuluan}

Metode Survei Resistivitas Listrik adalah salah satu metode yang paling umum digunakan dalam eksplorasi geofisika (Samouelian et al., 2005). Vertical Electrical Sounding (VES) adalah teknik geofisika yang paling banyak digunakan untuk pencarian air tanah, penafsirannya telah mengalami beberapa ketidaktegasan dan upaya untuk mengatasinya (Dewashish, 2007). Sebuah survei resistivitas geolistrik dilakukan untuk menyelidiki dugaan fitur karst bawah permukaan, seperti rongga, puncak, dan saluran yang terkubur di area batu kapur yang dipilih, di tambang yang ditinggalkan di Departemen Pekerjaan Umum (Jabatan Kerja Raya Malaysia, JKR) di tambang Batu Caves, Kuala Lumpur (AbuShariah, 2009). Keakuratan (perincian, resolusi) dari pencarian calon sumber listrik adalah kombinasi dari beberapa elemen yang berbeda, untuk menyebutkan hanya tiga: parameter 
yang telah ditetapkan dan, akibatnya, jenis bidang yang digunakan (dasar fisik), praktik teknis (respons recording) , dan kerangka model yang digunakan dalam interpretasi (Mogilatov, 2012).

Resistivitas semu dihitung untuk berbagai nilai pemisahan antara elektroda menggunakan nilai potensial antara elektroda pengukur dan fungsi yang diusulkan yang mencirikan perilaku elektroda yang digunakan yang secara substansial meningkatkan pengukuran untuk kedalaman kecil (Falerio, 2004). 2017). Pengetahuan rinci tentang struktur listrik tanah berguna dalam bidang-bidang seperti pertambangan, geofisika lingkungan, teknik, hidrologi dan ilmu-ilmu tanah antara lain (Loke et al., 2013). Dalam vertikal sounding listrik (VES) parameter akan dilakukan dalam menentukan bawah permukaan lokasi titik pengukuran. Tetapi sebagian besar dari mereka yang telah melakukan sounding elektrik vertikal untuk berbagai kebutuhan, tidak membahas proses inversi dari iterasi dan root berarti kuadrat. Pada intinya dalam vertical electrical sounding (VES) adalah hasil dari 1D, sehingga ketika akuisisi berada dalam prosedur untuk mengambil data dengan posisi peregangan yang berbeda, itu harus memiliki data yang berbeda untuk memvalidasi data yang telah ditafsirkan. Penelitian ini dimaksudkan untuk melihat penentuan hasil interpretasi data dari titik penelitian yang sama dengan rentang yang berbeda untuk menghasilkan data interpretasi yang sama.

Dalam vertikal electrical sounding (VES) akan ditemukan banyak parameter dalam menentukan bawah permukaan lokasi titik pengukuran. Tetapi sebagian besar dari mereka yang telah melakukan sounding elektrik vertikal untuk berbagai kebutuhan, tidak membahas proses inversi dari iterasi dan root berarti kuadrat. Pada intinya dalam vertical electrical sounding (VES) adalah hasil dari 1D, sehingga ketika akuisisi berada dalam prosedur untuk mengambil data dengan posisi peregangan yang berbeda, itu harus memiliki data yang berbeda untuk memvalidasi data yang telah ditafsirkan. Penelitian ini dimaksudkan untuk melihat penentuan hasil interpretasi data dari satu titik penelitian yang sama dengan akuisisi data yang berbeda untuk menghasilkan data interpretasi yang sama. Sehingga penentuan bawah permukaan menggunakan vertical electrical sounding (VES) bisa lebih tepat dan akurat.

\section{Metode Penelitian}

Metode geolistrik merupakan metode yang dalam penggunaannya menggunakan medan potensial listrik di bawah permukaan sebagai objek pengamatan utamanya. Penerapannya adalah dengan cara mengukur tahanan jenis (resistivity) dari suatu batuan. Pengukuran geolistrik ini arus listrik diinjeksikan ke dalam bumi menggunakan dua buah elektroda potensial.

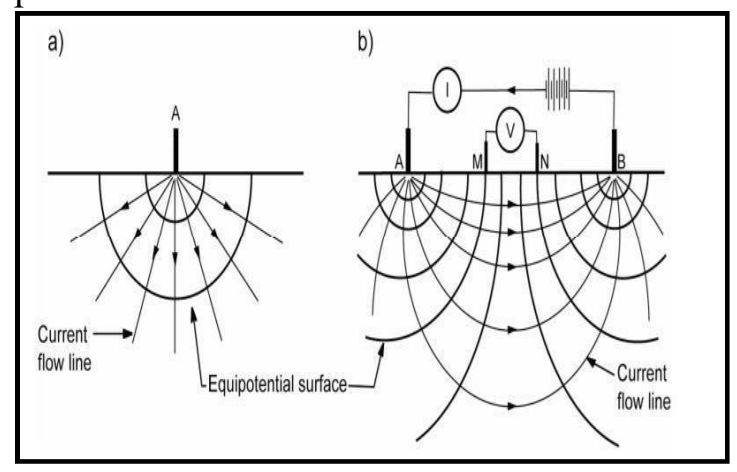


Gambar 1 (a) Sumber Arus Tunggal,

(b) Sepasang Elektroda Arus dan

Potensial

Konfigurasi Schlumberger ini dalam pengukurannya hampir sama dengan konfigurasi Wenner, akan tetapi jarak elektroda arus dapat diubah yang tidak sama dengan jarak dari elektroda potensialnya. Konfigurasi Schlumberger ini memiliki nilai eksentrisitas $1 / 3$ atau 1/5. Penggunaan konfigurasi Schlumberger ini pada umumnya digunakan untuk sounding, yang merupakan cara pengambilan data secara vertikal. Konfigurasi Schlumberger ini memiliki kelebihan yaitu dapat mendeteksi adanya nonhomogenitas dari suatu lapisan batuan pada permukaan. Sedangkan kelemahan dalam konfigurasi Schlumberger ini adalah pembacaan pada elektroda $\mathrm{MN}$ (elektroda potensial) akan kecil ketika AB (elektroda arus) berada sangat jauh. Kedalaman semu yang dimiliki oleh konfigurasi Schlumberger ini adalah sebesar $1 / 5$ dari bentangan $\mathrm{AB}$ (elektroda arus). Hasil dari pengukuran besarnya arus dan beda potensial akan didapatkan persamaan nilai resistivitas: $\rho a=K . R$

$\rho=K \frac{\Delta V}{I}$

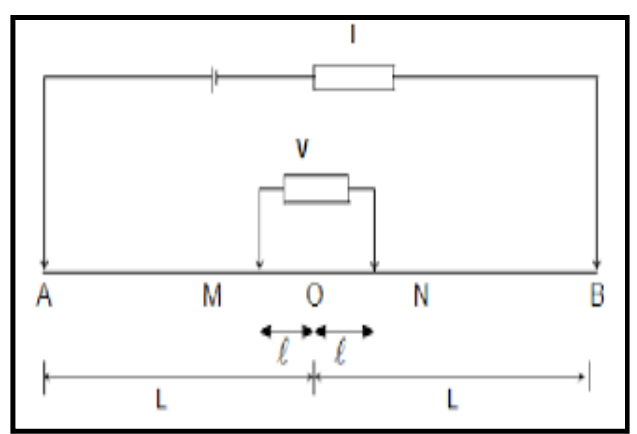

Gambar 2. Konfigurasi Schlumberger

Faktor geometri digunakan persamaan:

$$
\begin{aligned}
& \mathrm{Ps}=\mathrm{Ks} \frac{\Delta V}{\mathrm{I}} \\
& \mathrm{Ks}=\frac{\pi\left(\mathrm{L}^{2}-\mathrm{l}^{2}\right)}{2 \mathrm{l}}
\end{aligned}
$$

Sedangkan untuk mencari nilai faktor geometri (k) menggunakan rumus:

$$
\begin{aligned}
\mathrm{K} & =\frac{2 \pi}{\frac{1}{\mathrm{~b}-\mathrm{a} / 2}-\frac{1}{\mathrm{~b}+1 / 2}-\frac{1}{\mathrm{~b}+\mathrm{a} / 2}-\frac{1}{\mathrm{~b}-\mathrm{a} / 2}} \\
\mathrm{~K} & =\pi\left(\frac{\mathrm{b} 2}{\mathrm{a}}-\frac{\mathrm{a}}{4}\right) \\
\mathrm{K} & =\frac{2 \pi}{\frac{1}{\mathrm{C} 1 \mathrm{P} 1}-\frac{1}{\mathrm{C} 2 \mathrm{P} 1}-\frac{1}{\mathrm{C} 1 \mathrm{P} 2}+\frac{1}{\mathrm{C} 2 \mathrm{P} 2}}
\end{aligned}
$$

Faktor geometri Schlumberger secara umum yaitu:

$$
\mathrm{k}=\pi \frac{\mathrm{AB}^{2}-\mathrm{MN}^{2}}{4 \mathrm{MN}}
$$

Keterangan:

$\rho=$ Resistivitas Semu

$0=$ Titik yang diukur secara sounding

$\mathrm{AB}=$ Spasi Elektroda Aus (m)

$\mathrm{MN}=$ Spasi Elektroda Potensial (m), $\mathrm{MN}<1 / 5 \mathrm{AB}$

$\mathrm{k}=$ Faktor Geometri

\section{Hasil dan Pembahasan}

Secara topografi daerah penelitian tersebut termasuk daerah dataran karena memiliki kontur yang renggang. Elevasi pada daerah penelitian berada pada ketinggian 697 mdpl. Dapat dilihat pada Gambar 1 Peta Topografi. 


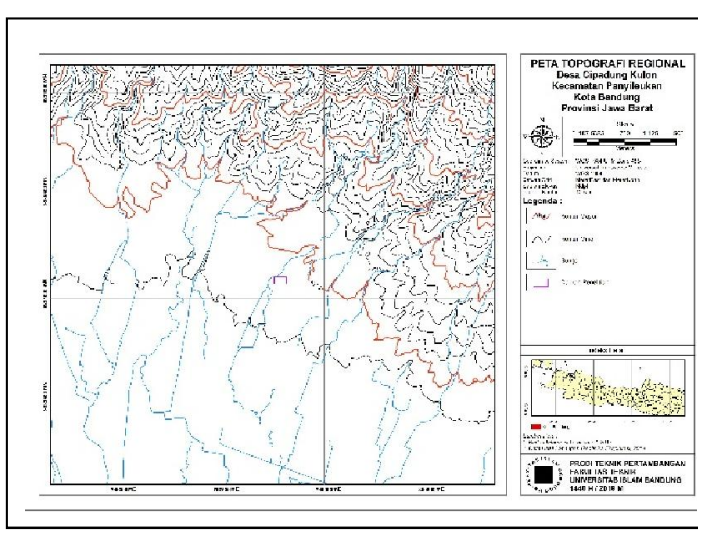

Gambar 3. Peta Topografi Penelitian

Secara geologi regional daerah penelitian berada pada formasi batuan Q1 yang dimana merupakan ENDAPAN DANAU (0-125 m) - Lempung tufaan, batupasir tufaan, kerikil tufaan. Membentuk bidang - bidang perlapisan mendatar di beberapa tempat. Mengandung kongkresi - kongkresi gamping, sisa - sisa tumbuhan, moluska air tawar dan tulang- tulang binatang bertulang belakang. Setempat mengandung sisipan breksi. Dapat dilihat pada Gambar 2 Peta Geologi.

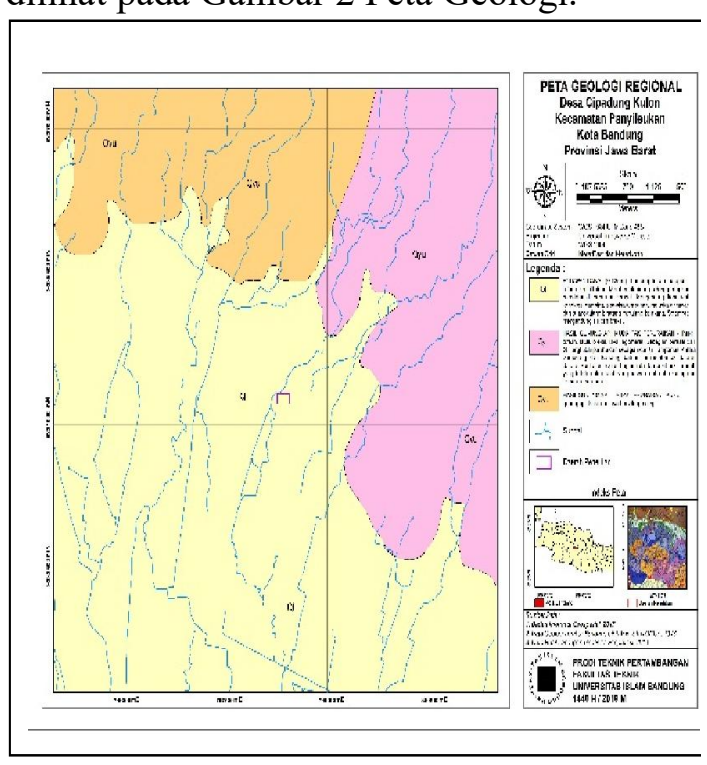

Gambar 4. Peta Geologi Daerah Penelitian

Pengukuran tahanan jenis di daerah penelitian tersebut ialah pengukuran tahanan jenis semu. Data tahanan jenis semu tersebut harus diolah untuk mendapatkan tahanan jenis sebenarnya. Dalam penelitian kali ini pengolahan tahanan jenis semu untuk mendapatkan tahanan jenis sebenranya

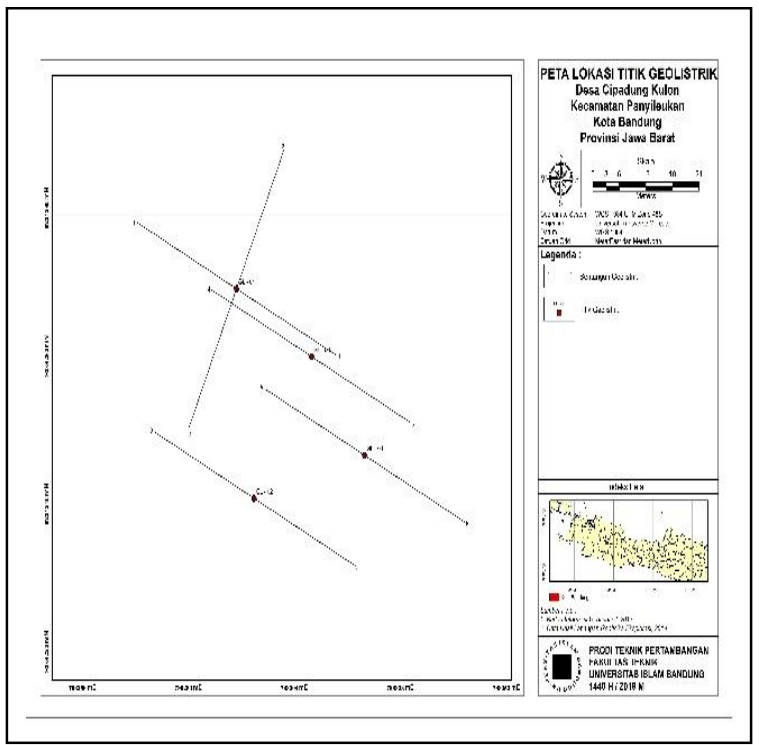

diolah secara manual menggunakan kurva baku dan kurva bantu.

Gambar 5. Peta Lokasi Titik Geolistrik 


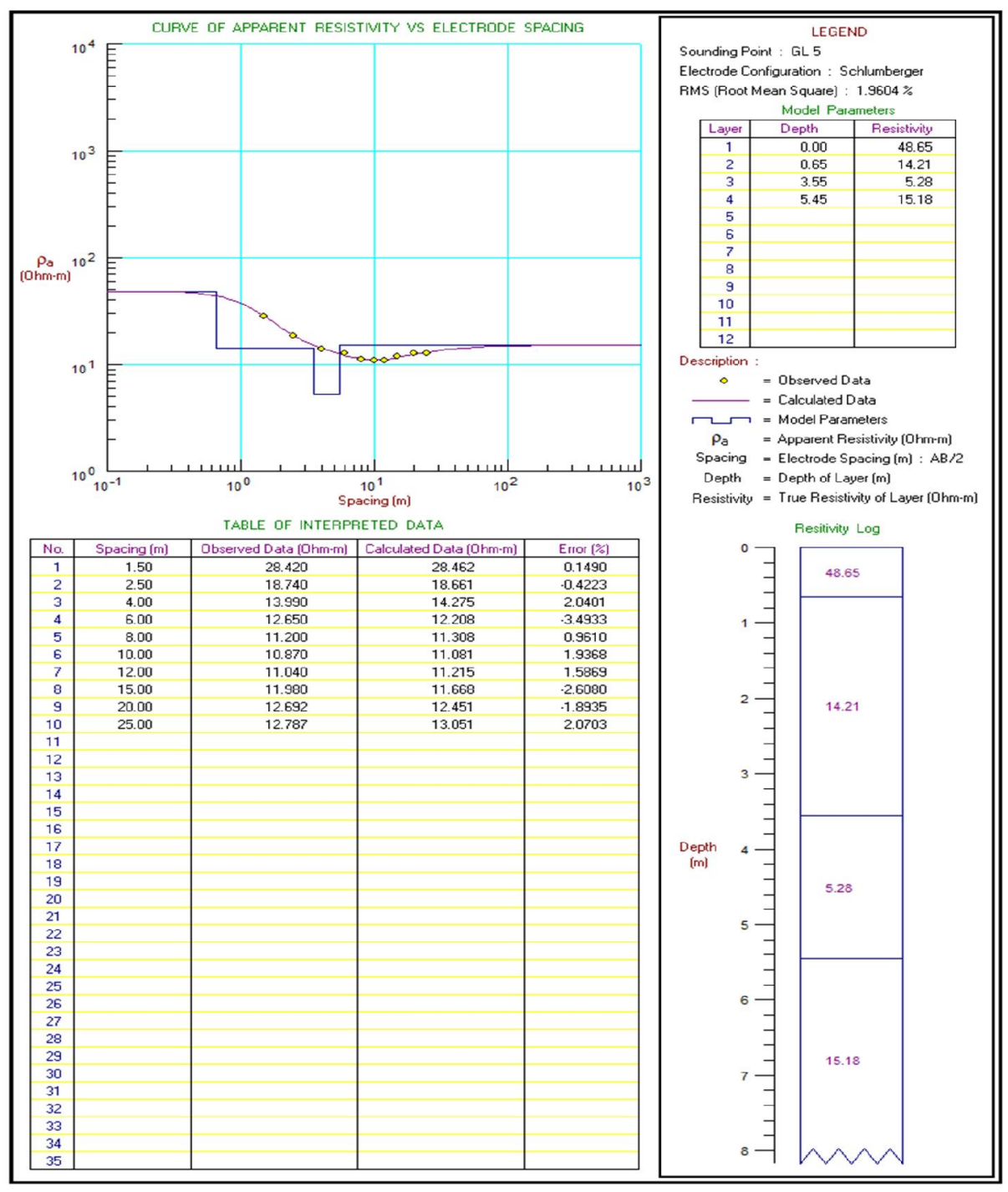

Gambar 5. Contoh Salah Satu Hasil Pengolahan Data Vertical electrical Sounding (VES)

Hasil pengolahan yang didapatkan berupa tahanan jenis sebenarnya yang diinterpretasi menggunakan perangkat lunak PROGRESS untuk disesuaikan iterasi dan Root Mean Square (RMS) agar didapatkan ketebalan dari Top Soil pada daerah penelitian tersebut.

Pada titik geolistrik 1 dilakukan pengukuran 2 bentangan yang saling berpotongan dengan arah bentangan pertama yaitu $\mathrm{N} 116^{\circ} \mathrm{E}$ dan arah bentangan kedua yaitu $\mathrm{N} 206^{\circ}$ E serta bentangan pada titik geolistrik 2, 3 dan 4 arahnya mengikuti bentangan yang pertama. 


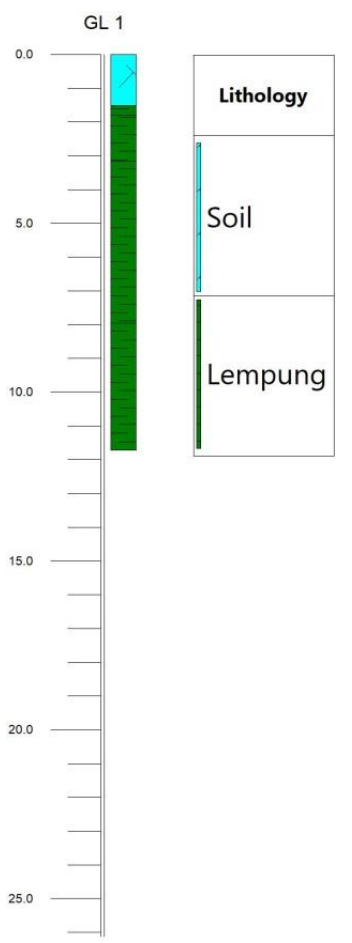

Gambar 6. Hasil Interpretasi Data Vertical Electrical Sounding (VES)

Berdasarkan hasil interpretasi data geolistrik tersebut didapatkan ketebalan Top Soil yaitu 1,35 meter yang didapatkan dari perpotongan grafik Iterasi dan kedalaman.

Tabel 1. Hubungan Interasi dengan kedalaman dan RMS

\begin{tabular}{|c|c|c|c|c|}
\hline \multirow{2}{*}{$\begin{array}{c}\text { Itera } \\
\text { si }\end{array}$} & \multicolumn{2}{|c|}{ Bentangan 1 } & \multicolumn{2}{c|}{ Bentangan 2 } \\
\cline { 2 - 5 } & $\begin{array}{c}\text { Dept } \\
\mathbf{h}(\mathbf{m})\end{array}$ & RMS & $\begin{array}{c}\text { Dept } \\
\mathbf{h}(\mathbf{m})\end{array}$ & RMS \\
\hline 0 & $\begin{array}{c}1,50 \\
0\end{array}$ & $\begin{array}{c}11,2546 \\
\%\end{array}$ & $\begin{array}{c}1,65 \\
0\end{array}$ & $\begin{array}{c}10,7541 \\
\%\end{array}$ \\
\hline 1 & $\begin{array}{c}1,49 \\
0\end{array}$ & $\begin{array}{c}10,8695 \\
\%\end{array}$ & 1,52 & 10,4520 \\
& 0 & 5 & $\%$ \\
\hline 2 & 1,42 & 10,5639 & 1,47 & $9,9523 \%$ \\
& 0 & $\%$ & 5 & \\
\hline 3 & 1,40 & 10,3567 & 1,41 & $9,5632 \%$ \\
\hline
\end{tabular}

\begin{tabular}{|c|c|c|c|c|}
\hline 4 & $\begin{array}{c}1,35 \\
0\end{array}$ & $\begin{array}{c}10,2672 \\
\%\end{array}$ & $\begin{array}{c}1,39 \\
0\end{array}$ & $9,3543 \%$ \\
\hline 5 & $\begin{array}{c}1,24 \\
0\end{array}$ & $8,9400 \%$ & $\begin{array}{c}1,35 \\
0\end{array}$ & $9,0216 \%$ \\
\hline 6 & $\begin{array}{c}1,22 \\
0\end{array}$ & $8,0258 \%$ & $\begin{array}{c}1,33 \\
3\end{array}$ & $8,4317 \%$ \\
\hline 7 & $\begin{array}{c}0,90 \\
0\end{array}$ & $7,0942 \%$ & $\begin{array}{c}1,31 \\
0\end{array}$ & $8,1076 \%$ \\
\hline 8 & $\begin{array}{c}0,92 \\
0\end{array}$ & 6,7999\% & $\begin{array}{c}1,29 \\
0\end{array}$ & $8,0168 \%$ \\
\hline 9 & $\begin{array}{c}0,93 \\
0\end{array}$ & $6,5518 \%$ & $\begin{array}{c}1,29 \\
0\end{array}$ & $7,8418 \%$ \\
\hline 10 & $\begin{array}{c}0,83 \\
0\end{array}$ & $6,4998 \%$ & $\begin{array}{c}1,30 \\
0\end{array}$ & $7,8196 \%$ \\
\hline 12 & $\begin{array}{c}0,81 \\
0\end{array}$ & $6,1413 \%$ & $\begin{array}{c}1,28 \\
0\end{array}$ & $7,7053 \%$ \\
\hline 14 & $\begin{array}{c}0,80 \\
0\end{array}$ & $6,0616 \%$ & $\begin{array}{c}1,25 \\
0\end{array}$ & $7,6164 \%$ \\
\hline 16 & $\begin{array}{c}0,79 \\
0\end{array}$ & $5,9475 \%$ & $\begin{array}{c}1,21 \\
0\end{array}$ & $7,5315 \%$ \\
\hline 18 & $\begin{array}{c}0,76 \\
0\end{array}$ & $5,8297 \%$ & $\begin{array}{c}1,20 \\
0\end{array}$ & $7,4332 \%$ \\
\hline 20 & $\begin{array}{c}0,70 \\
0\end{array}$ & $5,5919 \%$ & $\begin{array}{c}1,10 \\
0\end{array}$ & $7,4032 \%$ \\
\hline 30 & $\begin{array}{c}0,61 \\
0\end{array}$ & $5,3025 \%$ & $\begin{array}{c}1,09 \\
0\end{array}$ & $7,1906 \%$ \\
\hline 35 & $\begin{array}{c}0,60 \\
0\end{array}$ & $4,8264 \%$ & $\begin{array}{c}0,86 \\
0\end{array}$ & $6,6790 \%$ \\
\hline 40 & $\begin{array}{c}0,60 \\
0\end{array}$ & $4,5974 \%$ & $\begin{array}{c}0,82 \\
0\end{array}$ & $6,6096 \%$ \\
\hline 45 & $\begin{array}{c}0,53 \\
0\end{array}$ & $4,4018 \%$ & $\begin{array}{c}0,72 \\
0\end{array}$ & $6,4450 \%$ \\
\hline 50 & 0,49 & $4,1678 \%$ & 0,67 & $6,3669 \%$ \\
\hline
\end{tabular}

ISSN 1693-699X | EISSN 2502-065X 


\begin{tabular}{|c|c|c|c|c|}
\hline & 0 & & 5 & \\
\hline \multirow{2}{*}{60} & 0,47 & \multirow{2}{*}{$4,0119 \%$} & 0,64 & \multirow{2}{*}{$6,2973 \%$} \\
\hline & 0 & & 0 & \\
\hline \multirow{2}{*}{70} & 0,43 & \multirow{2}{*}{$3,9819 \%$} & 0,63 & \multirow{2}{*}{$6,0254 \%$} \\
\hline & 0 & & 0 & \\
\hline \multirow{2}{*}{80} & 0,40 & \multirow{2}{*}{$3,7852 \%$} & 0,57 & \multirow{2}{*}{$5,9854 \%$} \\
\hline & 0 & & 5 & \\
\hline \multirow{2}{*}{90} & 0,39 & \multirow{2}{*}{$3,5662 \%$} & 0,46 & \multirow{2}{*}{$5,8652 \%$} \\
\hline & 0 & & 0 & \\
\hline \multirow{2}{*}{100} & 0,32 & \multirow{2}{*}{$3,8652 \%$} & 0,35 & \multirow[b]{2}{*}{$5,7415 \%$} \\
\hline & 0 & & 0 & \\
\hline
\end{tabular}

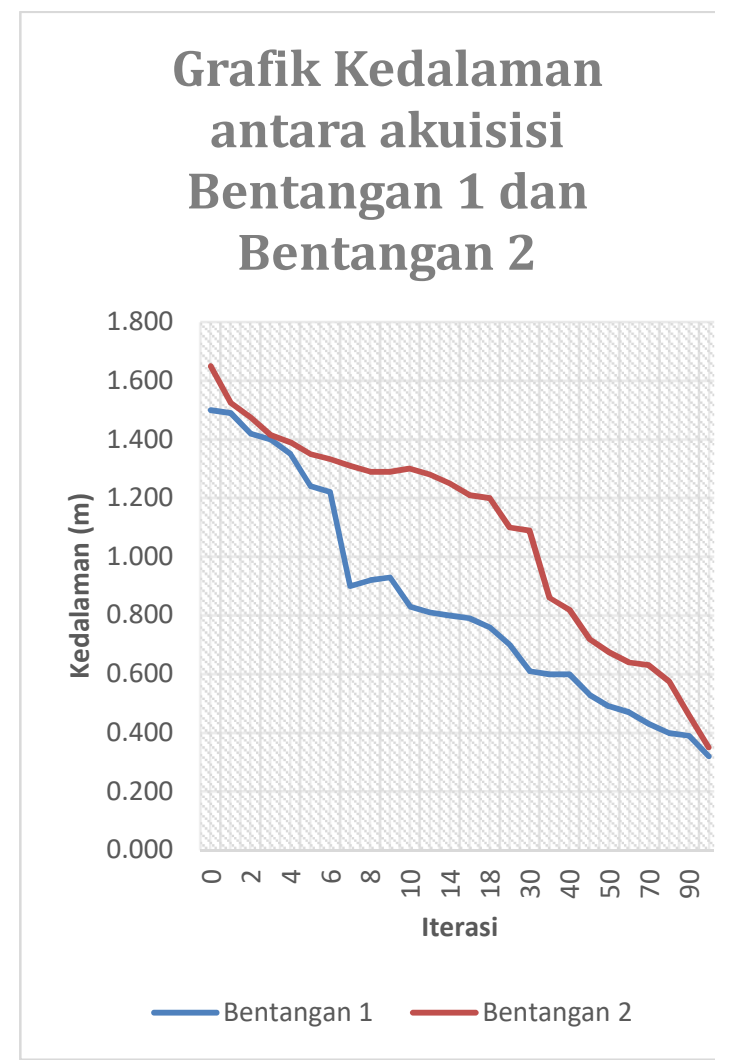

Gambar 4. Grafik Iterasi dan Kedalaman
Dari hasil interpretasi diatas menunjukan bahwa akan menghasilkan satu perpotongan saja. Sehingga perpotongan tersebut menjadi acuan untuk ketebalan Top Soil dan juga pada iterasi nya untuk menjadi acuan bentangan selanjutnya.

\section{Kesimpulan dan Saran}

Dari penelitian ini dapat diperoleh beberapa kesimpulan :

1. Berdasarkan hasil optimasi iterasi dan RMS, bahwa iterasi suatu lokasi berbeda akan menghasilkan sebuah litologi yang berbeda tergantung dari hasil interpretasi yang dihasilkam.

2. Root Means Square (RMS) yang semakin kecil bukan acuan yang baik untuk melakukan keputusan untuk melihat litologi bawah permukaan untuk metode vertical electrical sounding

3. Perlu ada masukan data lain untuk menginterpretasi suatu vertical electrical sounding (ves)

\section{Daftar Pustaka}

Abu-Shariah. 2009. Determination of cave geometry by using a geoelectrical resistivity inverse model. Engineering Geologi 105 (2009) 239-244.

Dewashish Kumar, Shakeel Ahmed, N.S. Krishnamurthy, Benoit Dewandel. 2007. Reducing Ambiguities In Vertical Electrical Sounding Interpretations: A Geostatistical Application. Journal of Applied Geophysics, https://doi.org/10.1016/j.jappgeo.20 06.07.001.

E. Faleiro, G. Asensio, J. Moreno. 2017. Improved measurements of the apparent resistivity for small depths in Vertical Electrical Soundings. 
Journal of Applied Geophysics 131, $117-122$.

Loke, M.H., Chambers, J.E., Rucker, D.F., Kuras, O., Wilkinson, P.B., 2013. J. Appl. Geophys.95, 135-156

Samouelian, A., Cousin, I., Tabbagh, A., Bruand, A., Richard, G., 2005. Soil Tillage Res. 83,173-193.

V.S. Mogilatov. 2012. Formation of the macroanisotropic geoelectric parameters of a thin-layered geologic medium and the resolution of electrical prospecting. Russian Geology and Geophysics 53, 484490. 